\title{
POLYMER COMPOSITE MANUFACTURING USING A PULTRUSION PROCESS: A REVIEW
}

\author{
${ }^{1}$ A.M. Fairuz, ${ }^{1,2,3}$ S.M. Sapuan, ${ }^{1}$ E.S. Zainudin and ${ }^{1}$ C.N.A. Jaafar \\ ${ }^{1}$ Department of Mechanical and Manufacturing Engineering, \\ ${ }^{2}$ Laboratory of Biocomposite Technology, Institute of Tropical Forestry and Forest Products (INTROP), \\ ${ }^{3}$ Aerospace Manufacturing Research Centre, Faculty of Engineering, \\ Universiti Putra Malaysia, 43400 UPM Serdang, Selangor, Malaysia
}

Received 2014-10-21; Revised 2014-10-23; Accepted 2014-10-25

Funding: The research work was funded by Universiti Putra Malaysia for research grant called Research University Grant Scheme (RUGS), project number 05-02-12-1916RU

Competing Interests: The authors have declared that no competing interests exist

\begin{abstract}
Pultrusion is the one of technologies to fabricate the polymer composites to be used in many industries such as in aerospace, automotive and construction industries. The high performance pultruded products that are produced by this technique offer high fibre content of at least $70 \%$. In order to produce high quality pultruded profiles, there are variables such as fibre impregnation, resin viscosity, pulling speed and curing temperature that have to be considered and these variables are discussed in this study. The review on the recent research in pultrusion process, types of resins used in pultrusion process and mechanical properties of pultuded composites are presented.
\end{abstract}

Keywords: Pultrusion Process, Composite Manufacturing, Thermoseting Polymer, Mechanical Properties, Resin Bath

\section{INTRODUCTION}

Advances in composite materials have penetrated into various industries such as automotive, aerospace, building, furniture and defense industries (Sapuan and Abdalla, 1998; Sapuan, 2005). Manufacturing process with composite components involved selection of suitable materials, design concepts and fabrication techniques. Among the fabrication techniques for composites include injection moulding, compression moulding, hand lay-up, spray up, moulding and pultrusion. Pultrusion is considered in this study. According to Hambali et al. (2009; 2010), selection of materials, manufacturing processes and conceptual design for composite materials is very vacuum bagging, filament winding, resin transfer

important because the wrong selection may lead to costly resigning of the products and purchase of alternative materials. Pultrusion was developed in the late $1950 \mathrm{~s}$ by W. Brant Goldsworthy and was patented as a method to make a fishing rod (Astrom et al., 1991; Shakya et al., 2013).

Pultrusion technique has become one of the important fibre reinforced polymer composite manufacturing techniques in the recent years and it is reported that it is the most cost effective technique for fabricating structural composite profile (Suratno and Ye, 1998). Pultrusion can also be used not only with conventional fibres like glass and carbon fibres but it can also be used with natural fibres in the form of continuous yarns (Sapuan, 2014) as these materials demonstrated comparable specific Corresponding Author: S.M. Sapuan, Department of Mechanical and Manufacturing Engineering, Universiti Putra Malaysia, 43400 UPM Serdang, Selangor, Malaysia, Tel.: +603-8947 1788, Fax: +60389471896 
properties with conventional fibres (Sastra et al., 2006; Sapuan et al., 2003; Anwar et al., 2009). But, the shape of the products is limited to continuous profiles such as rectangular, round tube, hollow square, bar and beam.

The fibres are impregnated with the low viscous liquid thermosetting polymer in the resin bath and then the pre-impregnated composites are pulled and cured through heated die (Carlsson and Astrom, 1998). According to Chandrashekhara et al. (2005), among the composite fabrication techniques like injection molding, pultrusion, extrusion and filament winding, pultrusion (Fig. 1) technique has been found to show better improvement in composite properties during processing because the fibers are pulled under tension when they entered the die as the reinforced composites are cured (Chandrashekhara et al., 2005).

Latere et al. (2004) reported that the increase of fibre loading in the fabrication of pultruded composites increased the mechanical and thermal properties of the composites. The major advantage of pultrusion process is high stiffness because of the higher fibre content in composites (more than 70\%) (Norlin et al., 2010).

Pultrusion process has been widely used for fabricating high performance products (Sumerak, 2004) (Fig. 2) and it has been used to produce sporting goods, corrosion resistance parts, architectural components, transport, agriculture, chemical engineering, electronic and electrical engineering, aircraft and aerospace (Ma et al., 1990).

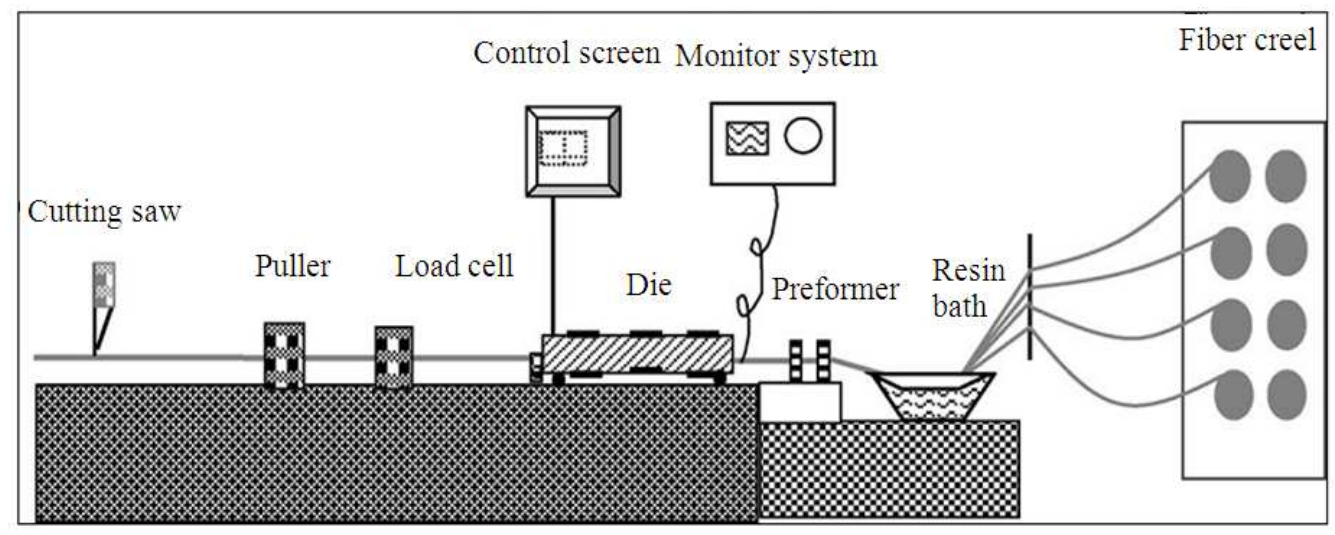

Fig. 1. Schematic representation of pultrusion process (Chandrashekhara et al., 2005)

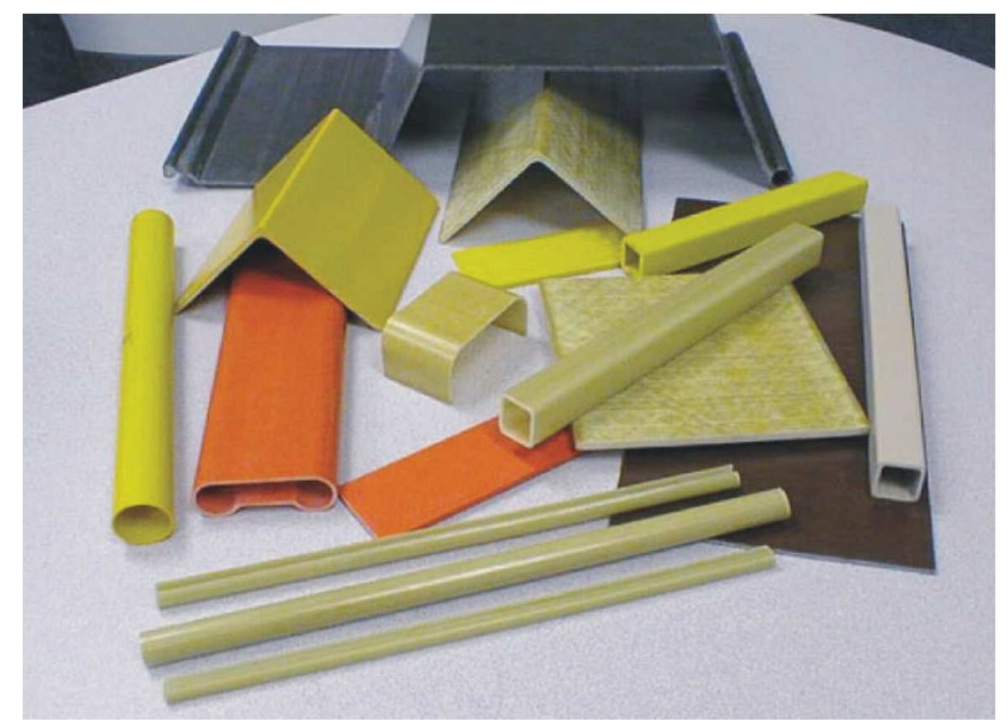

Fig. 2. Pultruded glass composite profile (Sumerak, 2004) 
This technology offers the integration of high volume fraction of fibre impregnation and composite consolidation in the same process (Giordano and Nicolais, 1997). The ease of production, the cost effectiveness and high productivity of this process made pultrusion one of the interesting methods over others for the fabrication fibre composite products (Sharma et al., 1998a; 1998b).

Pultruded profile has been successful in replacing conventional materials such as wood, Poly (Vinyl Chloride) (PVC) and aluminium in some engineering applications (Martin 2006). KaZaK, one of the U.S pultruded profile companies have been reported to develop pultruded composite vertical element which replaced steel stanchion in shipboard railing system (Jacob, 2006).

\section{PULTRUSION PROCESS}

Pultrusion is a continuous composite fabrication process where continuous reinforcing fibres are impregnated with thermosetting matrix and are pulled through a heated die to form composite profiles (Memon and Nakai, 2013). It has the capabilities to run continuously with constant cross section profile (Fig. 3) with the mass production volume.

Thermosetting pultrusion process can be divided into three zones; heat transfer zone, pressure zone and pulling zone (Moschiar et al., 1996a). Firstly, the fibres are pulled from the creel through a resin bath (Fig. 4) with the proper resin viscosity. Then, polymer solution is placed in the resin bath, which contains polymer resin, filler, catalyst, release agent, pigment, Ultra Violet (UV) stabilizer and other enhancement additives. Thereafter the fibres are guided by a guide plate where the fibres and resin are impregnated. The fibres are pulled through pre-form guides to eliminate excess resin before entering a heated die where the composites are cured.

The heated die (Fig. 5) in most of pultrusion process is divided into two zones; a low temperature for gelation and a high temperature to cure the resin. The pultrusion die is heated by a heater and the temperature is controlled using thermocouple sensor, which interacts with heater to ensure the temperature is sufficient and to avoid die from overheating which can cause the defect on the pultruded profile.

Generally, the continuous unidirectional fibres are impregnated with low viscosity thermosetting matrix before passing through the heated die for profile forming (Carlsson and Astrom, 1998). At this stage, the resinchanged from liquid to rubbery state and this transition is also known as gelation point or gel point and it continues to form solidified pultruded profile (Baran et al., 2013a).

The puller with the rubber clamp gripped the profiles and the profiles are pulled through the cutter and are cut to desired lengths. The clamp is controlled using pneumatic controller system and it is reported that pneumatic system is better than hydraulic clamp (which was used in older version pultruded machine) in protecting the profile. The pulling speed is controlled using a programming control system and it can be easily monitored and controlled in the monitor screen.

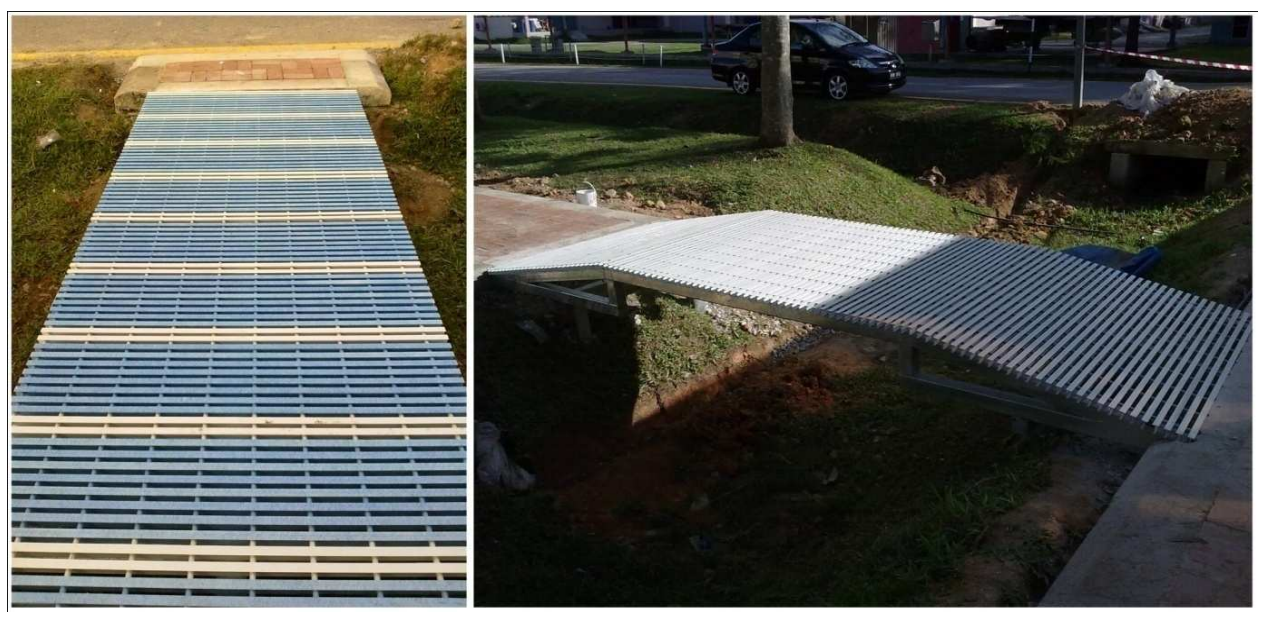

Fig. 3. Pultruded glass fibre composites grating for pedestrian bridge. (Courtesy of Rasidin Senawi, Innovative PultrusionSdn. Bhd. Seremban, Malaysia) 
A.M. Fairuz et al. / American Journal of Applied Sciences 11 (10): 1798-1810, 2014

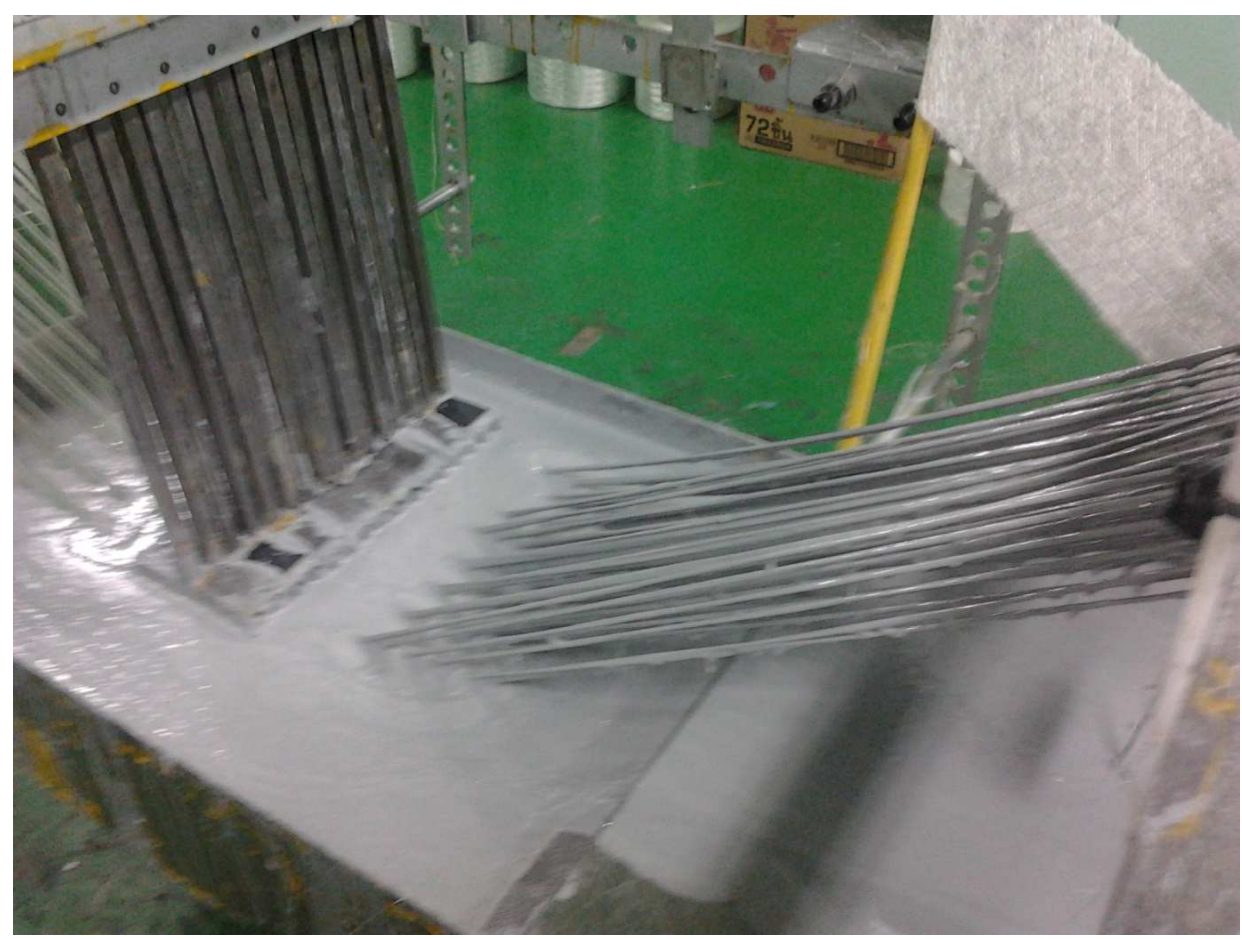

Fig. 4. Resin bath in pultrusion machine (Courtesy of Rasidin Senawi, Innovative Pultrusion Sdn. Bhd. Seremban, Malaysia)

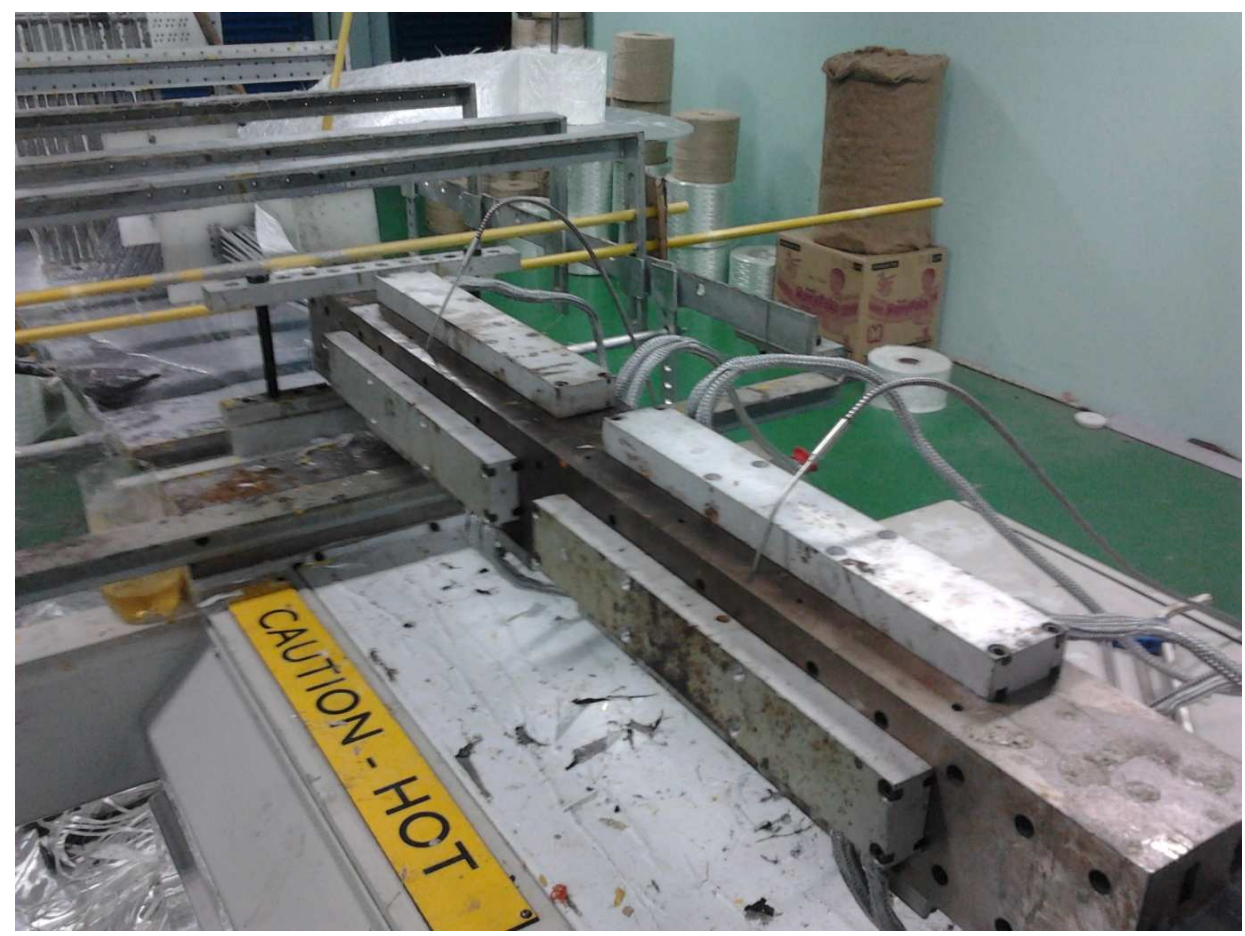

Fig. 5. Heated die for beam profile (Courtesy of Rasidin Senawi, Innovative PultrusionSdn. Bhd. Seremban, Malaysia) 
Another way to impregnate resin into the fibres is by injecting the polymer matrix through resin injection chamber into heated die. This type of impregnation method improves the wetting of the fibre composites and in turn improves the properties of the pultruded profile (Rahatekar and Roux, 2005).

\section{PROCESSING PARAMETERS}

The properties of the pultruded composites are influenced by the processing parameters. According to Lam et al. (2003), throughout the pultrusion process, there are factors that needed to be taken into account such as resin viscosity, fibre fraction, die temperature, resin polymerization and pulling speed. According to Santos et al. (2012), it is important to control the pultrusion process parameters in order to produce a profile with high quality.

In the early production of the pultrusion process, the heating occurred only in one section with single temperature set and it is difficult to control the heating temperature and the heating inside die due to strip heater, hot oil, or steam (Meyer, 1986). Implementing the technologies such thermocouple sensor and split heating zone in the pultrusion process improved the pultrusion productivity.

Among these variables, the curing temperature is the most significant factor that affects the pultruded profile during pultrusion process (Coelho and Calado, 2002). The matrix curing behaviour became the most critical factor in pultrusion process and it included the resin bonding behaviour, type and size of the die and the heater capacity. Different types of the resin system have their own behaviours and the promoter only acts as a bonding enhancement.

Even though the progress in the types of resin system has not taken place significantly in the last decade, continuous research is being carried out in understanding the behaviour of resins when they are being exposed to heat in order to improve the product quality and productivity. Coelho and Calado (2002) had reported that the non-uniform distribution of the degree of cure over the cross section had led to poor quality of the pultruded profiles. It is important to control the degree of cure during pultrusion process in order to produce good quality pultruded profiles (Lam et al., 2003). Uniform curing of the reinforcement improved the isotropic properties and homogeneity of pultruded profiles.

For that purpose, Astrom (1992) had developed pultrusion process model to study the temperature and pressure for pultruded composites and further research performed by Carlsson and Astrom (1998) investigated the thermal analysis of the pultrusion process to study the relation between heat transfer and crystallization kinetics to the speed of the pulling force. Liu et al. (2000) had developed heat transfer and the resin cure reaction models of pultrusion process. The development is based on finite element analysis and it gives an option to control the fibre volume fraction distribution, pulling speeds, resin cure kinetic, initial temperature, degree of cure profiles and different heating control method.

A separate heating zone in heated die improves the curing system of the pultruded profile based on gel and curing times. Moschiar et al. (1996b; Li et al., 2002) had studied the pultruded curing system by simulating using finite element analysis where the heated die is separated into three heating zones. Shokrieh and Aghdami (2011) developed three stage cure degree sections inside the heated die in pultrusion machine. They developed a three stage gel point model using finite element simulation to analyse the behavior of the resin in pultrusion process.

The volume of resin that shrinks has been a higher contribution to the deformation of the cured resin compared to thermal expansion because of the different temperatures of the resin and the die has become smaller (Baran et al., 2013b). Joshi et al. (2003) presented the analysis through finite element to study the behavior of pultruded glass reinforced epoxy composite at die inlet and die cooler temperature. In their previous work, Joshi and Lam (2006) had successfully developed 3D simulation using finite element/nodal control volume for thermoplastic and thermosetting matrices in pultrusion process.

There are many studies to optimize the parameters in order to improve the properties of the pultruded profiles either in terms of physical or mechanical properties. The pressure and temperature are important parameters to control in the pultrusion process (Astrom, 1992). The pressure is normally affected by the viscosity of the polymer matrix, fiber fraction, filler ratio, pulling speed and improper setting on the temperature (Gadam et al., 2000). Without a proper setting of the temperature, there is a tendency the reinforcement being trapped inside the die.

The velocity of the pulling speed must be controlled properly to reduce the pulling force through the pultrusion die (Fig. 6). The pulling force occurs starting from fibre creel until the die inlet and mostly occurs when cross linking reaction between polymer 
molecules inside heated die (Li et al., 2003). The factors that influenced the pulling speed of the composites during pultrusion process is frictional force, viscous force and internal die pressure (Lackey and Vaughan, 1994). When the velocity of the pulling speed reduces, the damage on the pultruded material can be reduced (Carlone and Palazzo, 2008).

Krasnovskii and Kazakov (2012) stated that optimal pulling speed should result in quality pultruded products with no cracks and fibre breakage. Smith (2007) reported that the increase of the amount of release agent in the polymer matrix formulation can reduce the pressure inside the die during pulling of the composites. However, the increase of release agent affects the quality of the pultruded products.

Astrom et al. (1991) performed theoretical modelling of a pultrusion process by optimizing important parameters such as temperature, pressure and process pulling force. Moschiar et al. (1996a) carried out a theoretical modelling of pulling speed for pultruded epoxy composites. They revealed that high pulling velocity reduces the thermal stress and pressure inside the heated die.

Chachad et al. (1996) studied the effect of pulling speed for different sizes of flat pultruded composites. Increasing pulling speed increases the degree of curing due to the high exothermic temperature at the center line. Also, the flat pultruded composites experienced lower degree of cure when pulling speed is reduced. Raper et al. (1999) developed a numerical model for flow through porous media which employs the finite volume method and among the parameters that they studied include the pressure and pulling speed in pultrusion die. In the developed model, the pulling speed, fibre volume fraction, matrix viscosity, guide plate and degree of cure affected the pressure.

Jeswani et al. (2009) also revealed that the increase of pulling speed improved the properties of the pultruded profile. Li et al. (2003) implemented mat tracer method and short die length method in studying the effect of die length on the pulling speed in pultrusion process. The increase of the die length does not affect the pulling force.

Fibres become compacted due to the viscosity of thermosetting resin in the pultrusion process. This would decrease the transverse permeability of the fibres thus would affect the wet out process (Shakya et al., 2013). Complete wet out of the fibers during pultrusion process leads to high quality pultruded profiles with good mechanical properties (Ranga et al., 2011; Chen et al.,
2002). Poor wetting mainly takes place due to high viscosity of resin.

Wilcox and Wright (1998) discussed some important parameters related to pultrusion process and developed artificial intelligent system to optimize the parameters involved. A 3 layer artificial neural network had been developed and it had the capability to analyse the parameters in order to choose the optimum combination of parameters to produce high quality pultruded composite products.

Sarrionandia et al. (2002) suggested that a key for optimization of the pultrusion process is to master the polymerization reaction in the pultrusion die. Giordano and Nicolais (1997) reported that die temperature, polymerization reaction, rheological change of resin and resin viscosities are the variables affecting the behaviour of the pultruded composites. They also explained that polymerization reaction and rheological change of the resin strongly influenced the final properties and the quality of the pultruded products.

\section{RESINS USED IN PULTRUSION PROCESS}

Baran et al. (2013b) highlighted that in pultrusion of thermo set composites, the exothermic reaction of the matrix begins when the composite reaches initiation temperature at which the gelation of the resin is also observed. Therefore, the thermosetting resin plays the important part in the degree of curing behaviour. There are some polymer matrices that have been used in pultrusion process such as polyester, vinyl ester, phenolic and epoxy (Vuppalapati et al., 2014). Each polymer matrix has its own specific characteristic advantages for processing, performance and application.

Polyester resin has been widely used to produce pultruded profiles (Tomlinson and Holland, 1994). Excellent performance and cost effectiveness provide the matrix the highest demand in current pultrusion manufacturing field. However, polyester is poor to resist the high temperature and is quit brittle.

Phenolic has the ability to withstand very high temperature compared to other polymers and it is widely applied in oil and gas industry. However, the pultrusion process with phenolic is quite difficult performed where many additives are required during the formulation process. Phenolic is normally possessed high viscosity and hence it is related to poor wetting characteristics and it leads to poor mechanical performances. To reduce the viscosity of phenolics, Ben et al. (2005) has suggested it 
should diluted with water. Yun and Lee (2008) introduced bubble in the phenolic foam and it can reduce the weight of the pultruded profiles.

Vinyl ester and epoxy demonstrated better wetting compared to other polymers because of their comparatively low viscosity. In addition, these materials can accommodate higher percentage of fibre thus they offer better mechanical and thermal performance. Epoxy shows much better mechanical performance compared to vinyl ester but the price of epoxy is higher than vinyl ester. Furthermore, epoxy is advantageous when special mechanical properties, thermal degradation and high corrosion resistance are required (Silva et al., 2012).

Martin (2013) reported that urethane resin providesthe highest glass loading compared to polyester and vinyl ester which leads to pultruded urethane composites to have flexural modulus properties approach the properties of aluminum (Fig. 7).

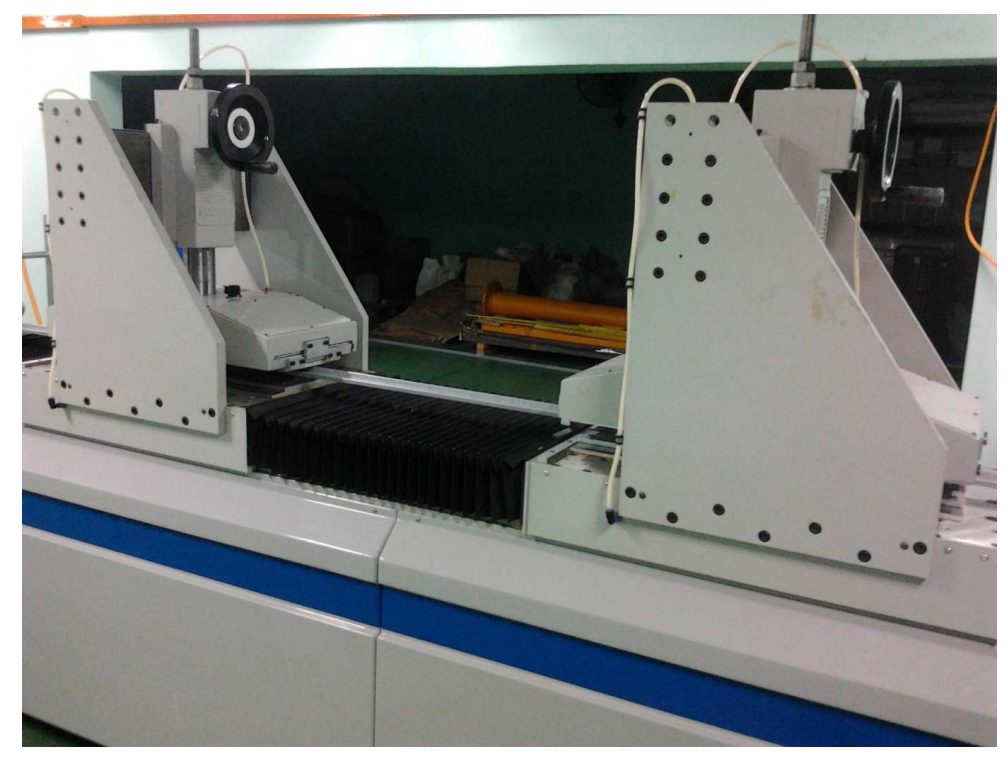

Fig. 6. Pneumatic puller in pultrusion process (Courtesy of Rasidin Senawi, Innovative PultrusionSdn. Bhd. Seremban, Malaysia)

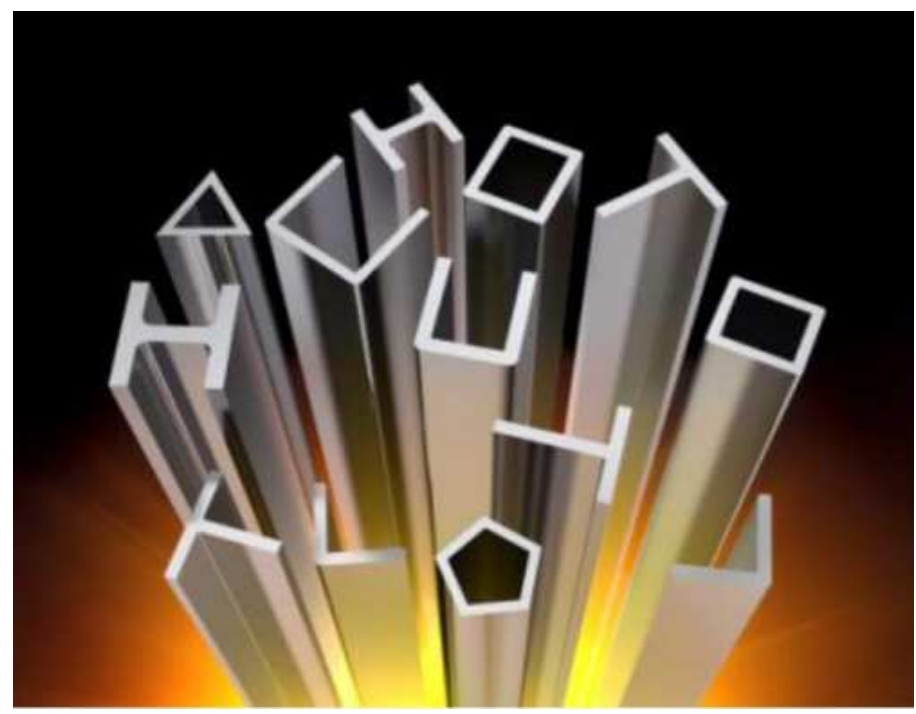

Fig. 7. Pultruded polyurethane composite profile (Martin, 2013) 


\section{MECHANICAL PROPERTIES OF PULTRUDED COMPOSITES}

Ma et al. (1997) studied mechanical and flame retardant properties of the pultruded Novolac type phenolic composites with different resin viscosities and curing temperatures. They designed three parts of the heating zones. The first heating zone at $110^{\circ} \mathrm{C}$ is for the cross linking reaction between formalin and residual phenol. For the second zone at $130^{\circ} \mathrm{C}$, hexamine, an additive, is converted to $\mathrm{NH}_{3}$ which acts like catalyst for the polymerization in the resin system. The third heating zone completely cured the resin and the composites became excellent flammability resistant pultruded profiles. The study also shows the effect of the different viscosities of Novolac phenolic resin on mechanical properties of the pultruded profiles. Figure $\mathbf{8}$ shows the viscosity of the Novolac type phenolic resin with $10 \%$ wt. hexamine and of the Resole type phenolic resin with $5 \%$ sulfonic acid.

Creighton and Clyne (2000) investigated compressive strength properties of pultruded carbon fibre reinforced epoxy composites. The compressive behaviour of two types of pultruded composite rods were compared. They used finite element modelling to assist a prediction of the compressive failure.

In the pultruded phenolic development, there are many additives added for polymerization of the resin system such as hexamine, formalin, release agent and filler. The addition of contain of the additives in composites should be optimized to retain the mechanical performance of materials. The purpose of adding filler such in resin system is to reduce the use of the polymer matrix and cost reduction. In addition, as reported by Lackey and Vaughan (1994) fillers such as calcium carbonate, hollow glass microspheres and liquid rubber are not only used to reduce the cost of the material but can also improve the impact resistance.

Generally, additive and fillers are used in the pultrusion process to enhance the physical and mechanical properties of the pultruded profiles, to solve production difficulty and to reduce the production cost (Boukhili et al., 2006).

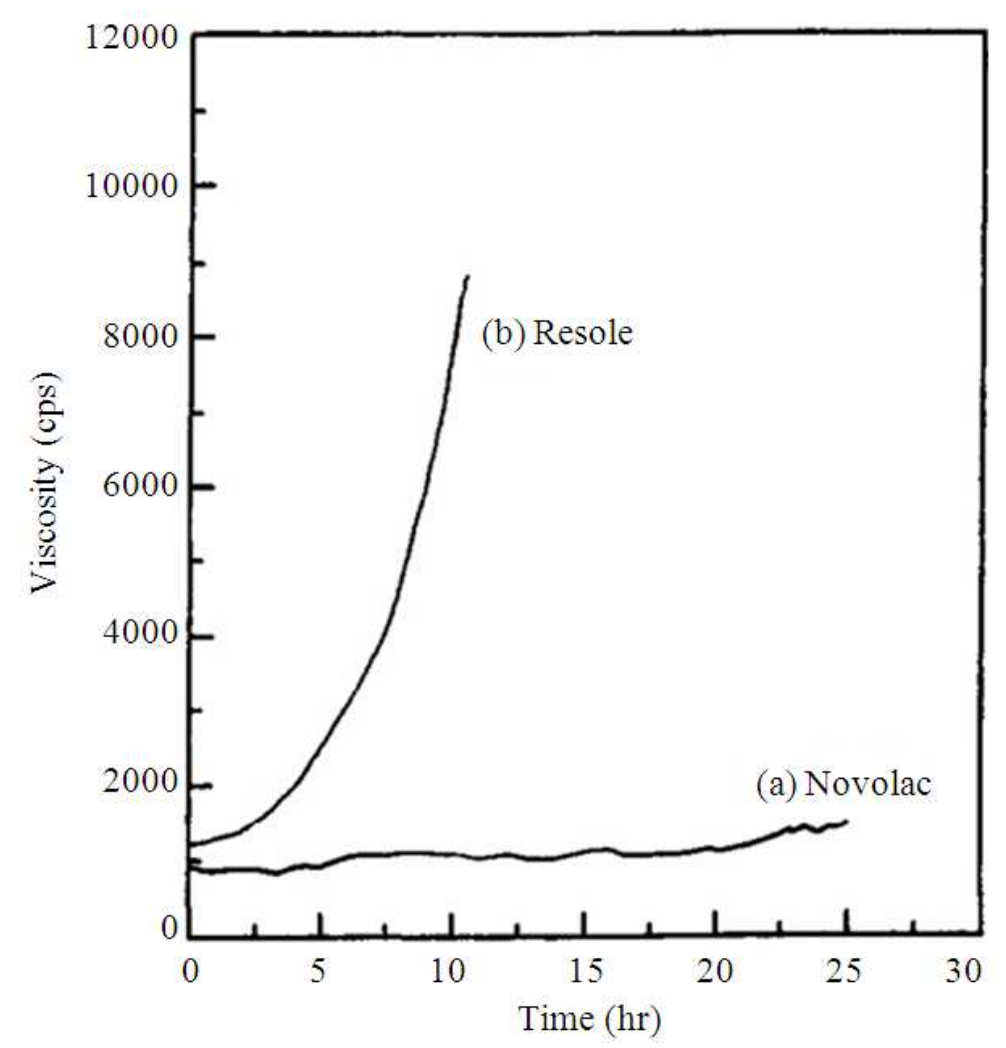

Fig. 8. The viscosity of the Novolac type phenolic resin with $10 \%$ wt. hexamine and of the Resole type phenolic resin with $5 \%$ sulfonic acid (Ma et al.,1997) 
Figure 9 shows typical load-displacement curves for pultruded glass/polyester composites containing different amounts of fillers and tested at $L / h=24$. Even though phenolic pultruded composites have been found as excellent resistance to fire, but the mechanical properties of this pultruded profile is worse compared to other types of pultruded profiles. Ma et al. (1997) studied the effect of the additive content called hexamine on mechanical properties of pultruded composites and revealed that $10-12 \%$ of hexamine content gave the maximum flexural strength.

Tsang et al. (1999) investigated the impact of fracture behaviour on the performance of pultruded glass fibre reinforced vinyl ester composites within the range of $20^{\circ} \mathrm{C}$ to $140^{\circ} \mathrm{C}$ and found that the pultruded composites are temperature sensitive. It shows that the resin is quite brittle when the temperature is increased but high volume fraction of fibres in the pultruded composites reduces the fracture failure. Figure $\mathbf{1 0}$ shows the maximum impact force $\left(F_{\max }\right)$ and fracture energy $\left(E_{b}\right)$ Vs temperature $\left({ }^{\circ} \mathrm{C}\right)$. Crea et al. (1997) studied the thermal effect on the tensile properties of pultruded glass fibre reinforced polyester composites. The results show that pultruded glass fibre reinforced polyester composites can withstand up to $250^{\circ} \mathrm{C}$ without losingtensile properties. Figure 11 shows tensile modulus of glass fibre reinforced composites with expose temperature.

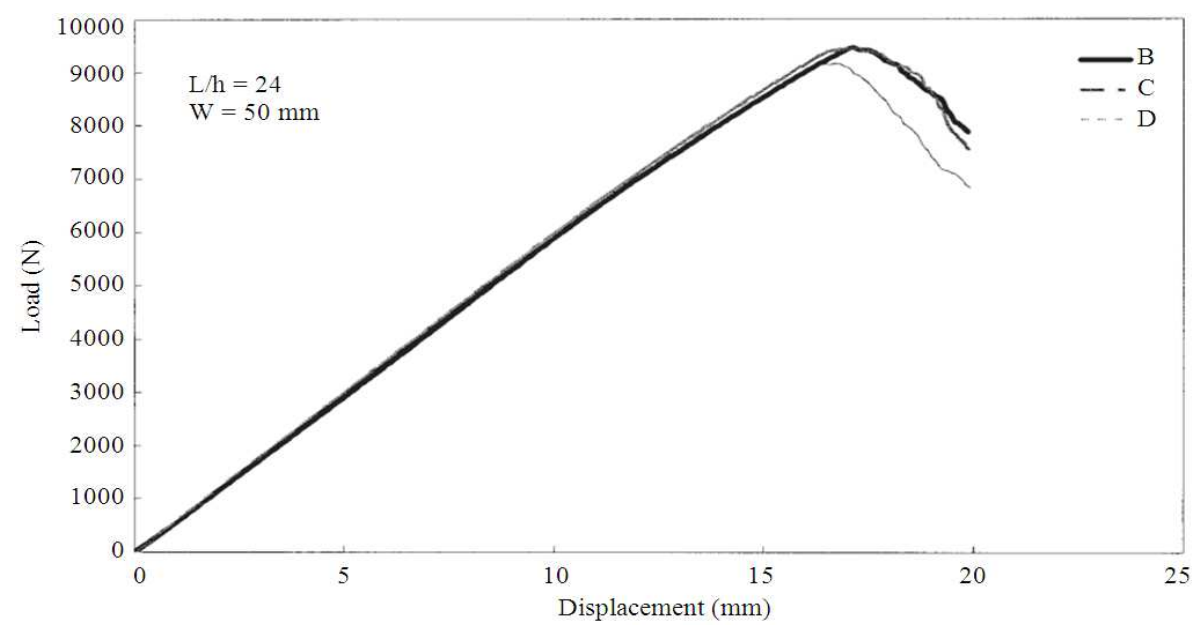

Fig. 9. Typical load-displacement curves for pultruded glass/polyester composites containing different amounts of fillers and tested at $\mathrm{L} / \mathrm{h} 24 .(\mathrm{l}=$ length, $\mathrm{h}=$ thickness, $\mathrm{B}=20 \%, \mathrm{C}=30 \%, \mathrm{D}=40 \%)$ (Boukhili et al., 2006)

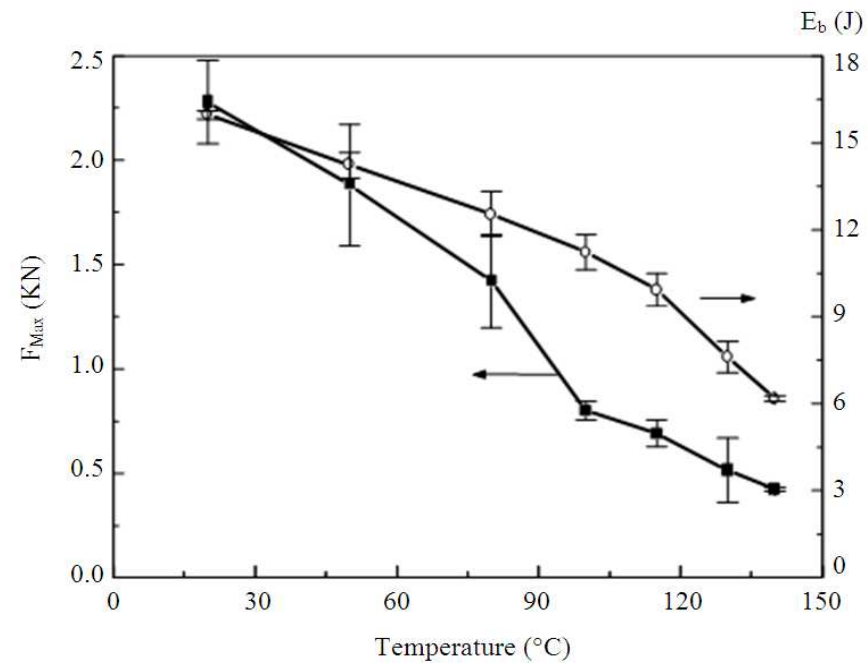

Fig. 10. Maximum impact force $\left(\mathrm{F}_{\max }\right)$ and fracture energy $\left(\mathrm{E}_{\mathrm{b}}\right) \mathrm{Vs}$ temperature $\left({ }^{\circ} \mathrm{C}\right)($ Tsang et al., 1999) 


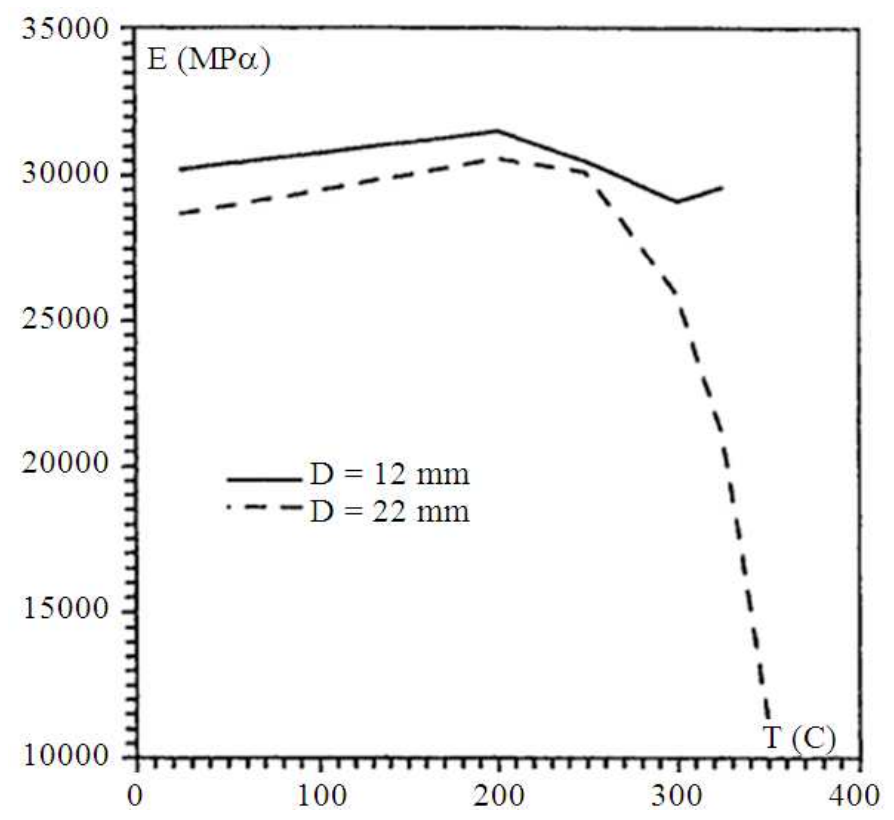

Fig. 11. Tensile modulus of glass fibre reinforced composites with expose temperature, (Crea et al., 1997)

\section{CONCLUSION}

Pultrusion process is one of the manufacturing processes for composite materials and it has the capability to produce composites with the fibre content of as high as $70 \%$ by weight. Furthermore, the process can produce pultruded composite components with fewer parameters during manufacturing compared to other composite fabrication processes. However, there are still scopes for improvement as far as manufacturing capability is concerned such as in the areas of the reinforcement, the heating behaviour and the pulling speed behaviours. Research on the modelling of pultruded composites to improve the manufacturing process should also be integrated with more realistic experimental works to verify the findings.

\section{ACKNOWLEDGEMENT}

The researchaers wish to thank Universiti Putra Malaysia for the funding support through Research University Grant Scheme (RUGS 2-2012), project number: 05-02-12-1916RU.

\section{ADDITIONAL INFORMATION}

\subsection{Funding Information}

The research work was funded by Universiti Putra Malaysia for research grant called Research
University Grant Scheme (RUGS), project number 0502-12-1916RU.

\subsection{Author's Contributions}

A.M. Fairuz: The principal author who carried out the research for his PhD work.

S.M. Sapuan: The corresponding author, responsible also as the main $\mathrm{PhD}$ supervisor, responsible to do content editing and English language editing.

E.S. Zainudin: Co-supervisor of $\mathrm{PhD}$ studies for A.M. Fairuz.

C.N.A. Jaafar: Co-supervisor of $\mathrm{PhD}$ studies for A.M. Fairuz.

\subsection{Ethics}

NIL.

\section{REFERENCES}

Anwar, U.M.K., M.T. Paridah, H. Hamdan, S.M. Sapuan and E.S. Bakar, 2009. Effect of curing time on physical and mechanical properties of phenolictreated bamboo strips. Indus. Crop. Prod., 29: 214219. DOI: 10.1016/j.indcrop.2008.05.003

Astrom, B.T., 1992. Development and application of a process model for thermoplastic pultrusion. Compos. Manuf., 3: 189-197. DOI: 10.1016/09567143(92)90082-6 
Astrom, B.T., P.H. Larsson and R.B. Pipes, 1991. Development of a facility for pultrusion of thermoplastic-matrix composites. Compos. Manuf., 2: 114-123. DOI: 10.1016/0956-7143(91)90188-M

Baran, I., C.C. Tutum, M.W. Nielsen and J.H. Hattel, 2013a. Process induced residual stresses and distortions in pultrusion. Compos. B: Eng., 51: 148161. DOI: 10.1016/j.compositesb.2013.03.031

Baran, I., C.C. Tutum, M.W. Nielsen and J.H. Hattel, 2013b. The effect of thermal contact resistance on the thermosetting pultrusion process. Compos. B: Eng., 45: 995-1000. DOI: 10.1016/j.compositesb.2012.09.049

Ben, G., A. Shoji and M. Souma, 2005. Development and Evaluation of FRP Sandwich Beams Containing Glass Fibers into Phenolic Foam Core. In: Sandwich Structures 7: Advancing with Sandwich Structures and Materials, Thomsen, O.T., E. Bozhevolnaya and A. Lyckegaard (Eds.)., Springer Netherlands, ISBN10: 978-1-4020-3444-2, pp: 1007-1016.

Boukhili, R., H. Boukehili, H. Ben Daly and A. Gasmi, 2006. Physical and mechanical properties of pultruded composites containing fillers and low profile additives. Polym. Compos., 27: 71-81. DOI: $10.1002 /$ pc. 20127

Carlone, P. and G.S. Palazzo, 2008. Viscous pull force evaluation in the pultrusion process by a finite element thermo-chemical rheological model. Int. J. Mater. Form., 1: 831-834. DOI: 10.1007/s12289008-0264-0

Carlsson, A. and B.T. Astrom, 1998. Modeling of heat transfer and crystallization kinetics in thermoplastic composites manufacturing: Pultrusion. Polym. Compos., 79: 352-359. DOI: 10.1002/pc.10108

Chachad, Y.R., J.A. Roux and J.G. Vaughan, 1996. Effects of pull speed on die wall temperatures for flat composites of various sizes. Reinf. Plast. Compos., 15: 718-739. DOI: $10.1177 / 073168449601500706$

Chandrashekhara, K., S. Sundararaman, V. Flanigan and S. Kapila, 2005. Affordable composites using renewable materials. Mater. Sci. Eng.: A., 412: 2-6. DOI: 10.1016/j.msea.2005.08.066

Chen, C.H., J.Y. Lue and C.C. Yen, 2002. In situ pultrusion of urea-formaldehyde matrix composites. I. Processability, kinetic analysis and dynamic mechanical properties. Appl. Polym. Sci., 83: 12421251. DOI: 10.1002/app.2291

Coelho, R.M.L. and V.M.A. Calado, 2002. An optimization procedure for the pultrusion process based on a finite element formulation. Polym. Compos., 23: 329-341. DOI: 10.1002/pc.10435
Crea, F., G. Porco and R. Zinno, 1997. Experimental evaluation of thermal effects on the tensile mechanical properties of pultruded GFRP rods. Appl. Compos. Mater., 4: 133-143. DOI: 10.1023/A:1008803122902

Creighton, C.J. and T.W. Clyne, 2000. The compressive strength of highly-aligned carbon-fibre/epoxy composites produced by pultrusion. Compos. Sci. Technol., 60: 525-533. DOI: 10.1016/S02663538(99)00153-0

Gadam, S.U.K, J.A. Roux, T.A. Mccarty and J.G. Vaughan, 2000. The impact of pultrusion processing parameters on resin pressure rise inside a tapered cylindrical die for glass-fibre/epoxy composites. Compos. Sci. Technol. 60: 945-958. DOI: 10.1016/S0266-3538(99)00181-5

Giordano, M. and L. Nicolais, 1997. Resin flow in a pultrusion process. Polym. Compos., 18: 681-686. DOI: $10.1002 /$ pc. 10320

Hambali, A., S.M. Sapuan, N. Ismail and Y. Nukman, 2009. Application of analytical hierarchy process in the design concept selection of automotive composite bumper beam during the conceptual design stage. Sci. Res. Essays., 4: 198-211.

Hambali, A., M.S. Sapuan, N. Ismail and Y. Nukman, 2010. Material selection of polymeric composite automotive bumper beam using analytical hierarchy process. J. Cent. South Univ. Technol., 17: 244-256. DOI: $10.1007 / \mathrm{s} 11771-010-0038-y$

Jacob, A., 2006. Globalisation of the pultrusion industry. Reinf. Compos., 50: 38-41.

Jeswani, A.L., J.A. Roux and J.G. Vaughan, 2009. Multiple injection ports and part thickness impact on wetout of high pull speed resin injection pultrusion. J. Compos. Mater., 43: 1991-2009. DOI: 10.1177/0021998308105542

Joshi, S.C., Y.C. Lam and U. Win Tun, 2003. Improved cure optimization in pultrusion with pre-heating and die-cooler temperature. Compos. A: Appl. Sci. Manuf., 34: 1151-1159. DOI: 10.1016/j.compositesa.2003.08.003

Joshi, S.C. and Y.C. Lam, 2006. Integrated approach for modelling cure and crystallization kinetics of different polymers in $3 \mathrm{~d}$ pultrusion simulation. $\mathbf{J}$. Mater. Process. Technol., 174: 178-182. DOI: 10.1016/j.jmatprotec.2006.01.003

Krasnovskii, A. and I. Kazakov, 2012. Determination of the optimal speed of pultrusion for large-sized composite rods. J. Encap. Adsorp. Sci., 2: 21-26. DOI: $10.4236 /$ jeas.2012.23004 
Lackey, E. and J.G. Vaughan, 1994. An analysis of factors affecting pull force for the pultrusion of graphite/epoxy composites. J. Reinf. Plast. Compos., 13: 188-198. DOI: 10.1177/073168449401300301

Lam, Y.C., J. Li and C.S. Joshi, 2003. Simultaneous optimization of die-heating and pull-speed in pultrusion of thermosetting composites. Polym. Compos., 24: 199-209. DOI: 10.1002/pc.10020

Latere, J.P.D., A.K. Mohanty, M. Misra, L.T. Drzal and M. Kazemizadeh, 2004. Biobased polyurethane and its composite with glass fiber. J. Mater. Sci., 39: 2081-2087.

DOI: 10.1023/B:JMSC.0000017770.55430.fb

Li, J., S.C. Joshi and Y.C. Lam, 2002. Curing optimization for pultruded composite sections. Compos. Sci. Technol., 62: 457-467. DOI: 10.1016/S0266-3538(02)00018-0

Li, S. L. Xu, Z. Ding, L.J. Lee and H. Engelen, 2003. Experimental and theoretical analysis of pulling force in pultrusion and Resin Injection Pultrusion (RIP)-Part I: Experimental. J. Compos. Mater., 37: 163-189. DOI: $10.1106 / 002199803028676$

Liu, L.X., I.G. Crouch and Y.C. Lam, 2000. Simulation of heat transfer and cure in pultrusion with a general-purpose finite element package. Compos. Sci. Technol., 60: 857-864. DOI: 10.1016/S02663538(99)00189-X

Ma, C.C.M. H.W. Wu, Y.F. Su, M.S. Lee and Y.D. Wu, 1997. Pultruded fiber reinforced novolac type phenolic composite-processability, mechanical properties and flame resistance. Compos. A: Appl. Sci. Manuf., 28: 895-900. DOI: 10.1016/S1359-835X(97)00051-1

Ma, C.C.M., M.S. Yn, C.H. Chen and C.L. Chiang, 1990. Processing and properties of pultruded thermoplastic composites (I). Compos. Manuf., 1: 191-196. DOI: 10.1016/0956-7143(90)90167-U

Martin, J., 2006. Pultruded composites compete with traditional construction materials. Reinf. Plast., 50: 20-27. DOI: 10.1016/S0034-3617(06)71008-6

Martin, P., 2013. Polyurethane pultrusion resin. Reinf. Plast., 57: 13-13. DOI: 10.1016/S00343617(13)70086-9

Memon, A. and A. Nakai, 2013. The processing design of jute spun yarn/PLA braided composite by pultrusion molding. Adv. Mech. Eng., 2013: 1-8. DOI: $10.1155 / 2013 / 816513$

Meyer, R. 1986. Handbook of Pultrusion Technology. 1st Edn., Springer Science and Business Media, Boston, ISBN-10: 1468477641.
Moschiar, S.M., M.M. Reboredo, M. Kenny and A. Vazquez, 1996a. Analysis of pultrusion processing of composites of unsaturated polyester resin with glass fibers. Polym. Compos., 17: 478-485. DOI: 10.1002/pc. 10636

Moschiar, S.M, M.M. Reboredo, H. Larrondo and A. Vazquez, 1996b. Pultrusion of epoxy matrix composites: Pulling force model and thermal stress analysis. Polym. Compos., 17: 850-858. DOI: 10.1002/pc. 10678

Norlin, N., H.M. Akil, Z.A. M. Ishak and A. Abu Bakar, 2010. Degradation of compressive properties of pultruded kenaf fiber reinforced composites after immersion in various solutions. Mater. Des., 31: 4960-4964. DOI: 10.1016/j.matdes.2010.04.037

Rahatekar, S.S. and J.A. Roux, 2005. Injection pultrusion simulation for polyester/glass mat/rovings/mat composites. J. Reinf. Plast. Compos., 24: 53-68. DOI: 10.1177/0731684405041719

Ranga, B.K., J.A. Roux, J.G. Vaughan and A.L. Jeswani, 2011. Effect of injection chamber length and pull speed of tapered resin injection pultrusion. J. Reinf. Plast. Compos., 30: 1373-1387. DOI: 10.1177/0731684411422415

Raper, K.S, J.A. Roux and T.A. McCarty, 1999. Investigation in behaviour in pultrusion die for graphite/epoxy composite. Compos. A: Applied Sci. Manuf., 24: 53-68.

Santos, L.S., E.C. Biscaia, R.L. Pagano, V.M.A. Calado, 2012. CFD-optimization algorithm to optimize the energy transport in pultruded polymer composites. Brazil J. Chem. Eng., 29: 559-566. DOI: 10.1590/S0104-66322012000300013

Sapuan, S.M. and H.S. Abdalla, 1998. A prototype knowledge-based system for the material selection of polymeric-based composites for automotive components. Compos. A: Applied Sci. Manuf., 29: 731-742. DOI: 10.1016/S1359-835X(98)00049-9

Sapuan, S.M., 2005. A conceptual design of the concurrent engineering design system for polymericbasede composite automotive pedals. Am. J. Applied Sci., 2: 514-525. DOI: 10.3844/ajassp.2005.514.525

Sapuan, S.M., 2014. Tropical Natural Fibre Composites: Properties, Manufacture and Applications. 1st Edn., Springer Science + Business Media, Singapore, ISBN-10: 9812871551, pp: 124.

Sapuan, S.M., M. Harimi and M.A. Maleque, 2003. Mechanical properties of epoxy/coconut shell filler particle composites. Arab. J. Sci. Eng., 28: 171-181. 
Sarrionandia, M., I. Mondragon, S.M. Moschiar and M.M. Reboredo, 2002. Heat transfer for pultrusion of a modified acrylic/glass reinforced composite. Polym. Compos., 23: 21-27. DOI: 10.1002/pc.10408

Sastra, H.Y., J.P. Siregar, S.M. Sapuan and M.M. Hamdan, 2006. Tensile properties of Arenga pinnata fiber-reinforced epoxy composites. Polym. Plast. Technol. Eng., 45: 149-155. DOI: 10.1080/03602550500374038

Shakya, N., J.A. Roux and A.L. Jeswani, 2013. Effect of resin viscosity in fiber reinforcement compaction in resin injection pultrusion process. Applied Compos. Mater., 20: 1173-1193. DOI: 10.1007/s10443-013-9320-0

Sharma, D., T.A. Mccarty, J.A. Roux and G. Vaughan, 1998a. Fluid mechanics analysis of a twodimensional pultrusion die inlet. Polym. Eng. Sci., 38: 1611-1622. DOI: 10.1002/pen.10331

Sharma, D., T.A. Mccarty, G. Vaughan and J.A. Roux. 1998b. Pultrusion die pressure response to changes in die inlet geometry. Polym. Compos., 19: 180-192. DOI: $10.1002 / \mathrm{pc} .10089$

Shokrieh, M.M. and A.M. Aghdami, 2011. A Dynamic transient model to simulate the time dependent pultrusion process of glass/polyester composites. Applied Compos. Mater., 18: 585-601. DOI: 10.1007/s10443-011-9226-7

Silva, F.J.G. F. Ferreira, C. Costa, M.C.S. Ribeiro and A.C. Meira Castro, 2012. Comparative study about heating systems for pultrusion process. Compos. B: Eng., 43: 1823-1829. DOI: 10.1016/j.compositesb.2012.01.057
Smith, C., 2007. The impact of release agents on pultruded FRP, composite and polycon 2007, 17-19 Oct., Tampa, Fl.

Sumerak, J.E., 2004. Pultrusion gets tough. Compos. Fabric, 1: 16-27.

Suratno, B.R. and L. Ye, 1998. Simulation of temperature and curing profiles in pultruded composite rods. Compos. Sci. Technol., 58: 191197. DOI: 10.1016/S0266-3538(97)00132-2

Tomlinson, W.J. and J.R. Holland, 1994. Pultrusion and properties of unidirectional glass fibrepolypropylene matrix composites. J. Mater. Sci. Lett., 13: 675-677. DOI: 10.1007/BF00271231

Tsang, F.Y., J.Z. Liang, C.M. Tai, C.Y. Ching and R.K.Y. Li, 1999. Effects of temperature on impact fracture behavior of pultruded glass fiber-reinforced poly (vinyl ester) Composite. Int. Conf. Compos. Mater. Paris.

Vuppalapati, R.R., V.G.K. Menta, K. Chandrashekhara and T. Schuman, 2014. Manufacturing and impact characterization of soy-based polyurethane pultruded composites. Polym. Compos., 35: 1070-1077.

Wilcox, J.A.D. and D.T. Wright, 1998. Towards pultrusion process optimisation using artificial neural networks. J. Mater. Process. Technol., 83: 131-41. DOI: 10.1016/S0924-0136(98)00052-1

Yun, M.S. and W.I. Lee, 2008. Analysis of pulling force during pultrusion process of phenolic foam composites. Compos. Sci. Technol., 68: 202-208. DOI: 10.1016/j.compscitech.2007.05.032 